\title{
La Comisión de la Verdad en Colombia: conocimiento, percepción, eficacia y emociones asociadas
}

José Ignacio Ruiz' ${ }^{1}$ Pablo Castro-Abril², Wilson López-López ${ }^{3}$, Darío Páez ${ }^{4}$, Lander Méndez ${ }^{5}$, Suly Castro-Molinares ${ }^{6}$, Zulma Yadira-Cepeda ${ }^{7}$, María Alejandra Caicedo-Buchelii ${ }^{8}$, María del Carmen Amaris ${ }^{9}$, Jorge Eduardo Moncayo $^{10}$, Rossana Camelo-Mendoza ${ }^{11}$, Frank Steward Orduz-Gualdron ${ }^{12}$, Manuel Beltrán-Espitia ${ }^{13}$, Zulma Lorena Mongui ${ }^{14}$, Elsy Domínguez ${ }^{15}$, Argemiro Alejo-Riveros ${ }^{16}$,LuísEduardo Pérez-Cervantes ${ }^{17}$, Carolina Orozco Castillo $^{18}$, Laura Alvarado-Pinzón ${ }^{19}$, Jaime, Alberto Restrepo-Soto ${ }^{20}$, Edgar Alejo-Castillo ${ }^{21}$, Johnny Orejuela ${ }^{22}$, Areli Rocha ${ }^{23}$, Mar Pérez Arizabaleta ${ }^{24}$ Universidad Nacional de Colombia-Colombia, Universidad del País VascoEspaña, Pontificia Universidad Javeriana-Colombia, Universidad Nacional Abierta y a Distancia-Colombia, Universidad Surcolombiana-Colombia, Fundación Universitaria de Popayán-Colombia, Universidad del Norte-Colombia, Universidad Antonio Nariño-Colombia, Universidad Popular del Cesar-Colombia,

Universidad Simón Bolivar-Colombia, Universidad Claretiana-Colombia, Universidad Pedagógica y Tecnológica de Colombia-Colombia, Universidad Tecnológica de Bolivar-Colombia, Universidad de Ibagué-Colombia, Corporación Universitaria Antonio José de Sucre-Colombia, Universidad EAFIT-Colombia, Universidad de Manizales-Colombia, Universidad de Santander-Colombia

1 Doctor en Psicología. Profesor asociado en la Universidad Nacional de Colombia, Colombia. Dirección postal: Carrera 30 \# 45-03, Edificio 212, Of 220. Contacto: jiruizp@unal.edu.co. https://orcid.org/0000-0002-8996-9736

2 Doctor en Psicología. Investigador predoctoral en la Universidad del País Vasco, España. Dirección postal: Departamento de Psicología. Oficina 230. Carrera 30 - 45. Ciudad Universitaria, Bogotá, Colombia. Contacto: jiruizp@unal.ed.co. https://orcid.org/0000-0001-9074-3921

3 Doctor en Psicología. Profesor titular en la Pontificia Universidad Javeriana, Colombia. Dirección postal: Cra 5ta \# 39-00 Segundo Piso. Contacto: lopezw@javeriana.edu.co. https://orcid.org/0000-0002-2964-0402

4 Doctor en Psicología. Profesor catedrático en la Universidad del País Vasco, Espańa. Dirección postal: Av de Tolosa 70, 20011, Guipuzcoa, España. Contacto: Dario.paez@ehu.es. https://orcid.org/0000-0002-8459-6037

5 Doctor en Psicología. Investigador predoctoral en la Universidad del País Vasco, España. Dirección postal: Av. Tolosa, 70, 20018 San Sebastián/Donostia. Contacto: lander.mendez@ ehu.eus. https://orcid.org/0000-0001-7875-6949

6 Doctora en Ciencias de la Educación. Docente a tiempo completo en la Universidad Nacional Abierta y a Distancia, Colombia. Dirección postal: Carrera 45B No. 18-15 Sur Villavencio, Colombia. Contacto: sulycastro@gmail.com. https://orcid.org/0000-0002-2876-7401 
7 Magíster en Psicología. Profesora asistente en la Universidad Surcolombiana, Colombia. Dirección postal: Carrera 12 B No. 2-27 barrio surinama. Tunja (Boyacá). Contacto: zulma. cepeda@usco.edu.co. https://orcid.org/0000-0002-5520-5391

8 Licenciada en Psicología. Jefa del Centro de Investigación de Psicología en la Fundación Universitaria de Popayán, Colombia. Contacto: investigacion.psicologia@fup.edu.co. https:// orcid.org/0000-0002-1549-9989

9 Doctora en Psicología. Docente en la Universidad del Norte, Colombia. Dirección postal: 080020, Colombia. Contacto: mamaris@uninorte.edu.co. https://orcid. org/0000-0002-3229-7887

10 Doctor en Educación. Coordinador de Investigación en la Universidad Antonio Nariño, Sede Cali,Colombia.Contacto:jomoncayo@uan.edu.co.https://orcid.org/0000-0001-6458-4162

11 Licenciada en Psicología. Profesora en la Universidad Popular del César, Colombia. Dirección postal: 200001. Contacto: rossanacamelo@unicesar.edu.co. https://orcid. org/0000-0002-2081-9326

12 Magíster en Resolución de Conflictos y Mediación. Docente investigador en la Universidad Simón Bolívar, Colombia. https://orcid.org/0000-0002-5400-124X

13 Doctor en Psicología. Docente investigador en la Fundación Universitaria Clateriana, Universidad Clateriana, Colombia. Dirección postal: 27001 - 20 \#5-66 Barrio Yesquita. Contacto: dct.mbeltran@uniclaretiana.edu.co. https://orcid.org/0000-0001-6876-3088

14 Licenciada en Psicología. Docente en la Universidad Pedagógica y Tecnológica de Colombia, Colombia. Dirección postal: Cr 7 23-50 Tunja-Boyocá-Colombia, CP 15001. Contacto: zulma.mongui@uptc.edu.co. https://orcid.org/0000-0002-7937-7120

15 Doctora en Ciencias Sociales. Docente en la Universidad Tecnológica de Bolívar, Colombia. Contacto: edominguez@etup.edu.eco. https://orcid.org/0000-0001-8801-675X

16 Magíster en Psicología. Docente de tiempo completo en la Universidad de Ibague, Colombia. Contacto: argemiro.alejo@unibague.edu.co. https://orcid.org/0000-0002-8220-196X

17 Magíster en Derecho. Docente en la Corporación Universitaria Antonio José de Sucre, Colombia. Dirección postal: Urbanización castillete manzana C casa 11, Cartagena, Bolivar. Contacto: luis_perez@corposucre.edu.co. https://orcid.org/0000-0001-7847-7755

18 Licenciada en Psicología. Asistente de Investigación en la Universidad EAFIT, Colombia. Dirección postal: 055460, Colombia. Contacto: caro.orozco.castillo@gmail.com. https:// orcid.org/0000-0002-2307-9159

19 Doctora en Psicología. Investigadora en la Universidad del País Vasco, España. Dirección postal: Av. Tolosa, 70, 20013. Contacto: laura91.ap@gmail.com. https://orcid. org/0000-0001-9452-710X

20 Doctor en Ciencias Sociales. Profesor Titular en la Universidad de Manizales, Colombia. Dirección postal: Calle64B N ${ }^{\circ} 20^{\mathrm{a}} 55$, apartamento 303, Manizales, Colombia. Contacto: jaimea@umanizales.edu.co. https://orcid.org/0000-0003-3181-5424

21 Doctor en Psicología. Profesor en la Universidad de San Buenaventura, Colombia. Dirección postal: 050022, Colombia. Contacto: edalejo@gmail.com. https://orcid. org/0000-0002-7007-2435

22 Doctor en Psicología. Jefe del departamento de Psicología de la Universidad EAFIT, Colombia. Dirección postal: Calle 27 D sur 28-50. Contacto: jorejue2@eafit.edu.co. https:// orcid.org/0000-0001-9181-463X

23 Doctorando en psicología. Universidad del Norte. Dirección postal: 083005, Colombia. Contacto: arelir@uninorte.edu.co https://orcid.org/0000-0002-5527-5218

24 Magíster en Psicología. Docente Investigadora en la Universidad Antonio Nariño, Colombia. Contacto: maperez27@uan.edu.co. https://orcid.org/0000-0001-8537-6696 
La Comisión de la Verdad en Colombia se estableció a partir del modelo de justicia transicional. Su función es servir como medida de reconocimiento de los hechos violentos durante el conflicto armado, que han dejado más de nueve millones de víctimas. En este marco, se realizó un estudio descriptivo correlacional $(N=1166)$ con una muestra de 22 departamentos del país para evaluar el conocimiento, la aprobación y la efectividad percibida de los primeros ańos de la Comisión a partir de aspectos psicosociales: victimización, emociones colectivas, reconciliación, memoria colectiva. El 58\% eran víctimas directas. Los resultados indican altos niveles de aprobación y de disposición a participar en las actividades de la Comisión, así como cierto escepticismo sobre su utilidad y una baja confianza en las disculpas oficiales de los grupos en conflicto. También se encuentra un alto índice de emociones positivas relacionadas con la comisión y una baja confianza en las instituciones gubernamentales. Lo encontrado en este estudio, coincide con experiencias previas de comisiones de la verdad en Latinoamérica, y abre el debate sobre las especificidades del contexto colombiano en la búsqueda de paz y las implicaciones del trabajo de la comisión en el proceso de reparación. Palabras clave: Comisión Verdad Colombia, impacto psicosocial, justicia transicional, reparación a víctimas, reconciliación social.

\section{Colombian Truth Commission: Knowledge, perception, efficacy, and associated emotions}

The Truth Commission in Colombia was established based on the transitional justice model. Its function is to serve as a measure of recognition of the violent events during the armed conflict, which has left more than nine million victims. In this scenario, a descriptive correlational study $(N=1166)$ was conducted with a sample of 22 provinces of the country to evaluate the knowledge, approval, and perceived effectiveness of the first years of the Commission from psychosocial aspects: victimization, collective emotions, reconciliation, collective memory. 58\% were direct victims. The results indicate high levels of approval and disposition to participate in the Commission's activities, as well as some skepticism about its usefulness and low confidence in the official apologies of the groups in conflict. A high index of positive emotions related to the commission and low trust in government institutions is also found. The findings of this study coincide with previous experiences of truth commissions in Latin America and open the debate on the specificities of the Colombian context in the search for peace and the implications of the commission's work in the reparation process.

Keywords: Colombia`s Truth Commission, psychosocial impact, transitional justice, reparation to victims, social reconciliation.

\section{Comissão colombiana da Verdade: Conhecimento, percepção, eficácia e emoçóes associadas}

A Comissão da Verdade na Colômbia foi criada com base no modelo de justiça de transição. A sua função é servir de medida de reconhecimento dos acontecimentos violentos durante o conflito armado, que deixaram mais de nove milhóes de vítimas. Neste contexto, foi realizado um estudo descritivo correlacional $(\mathrm{N}=1166)$ com uma amostra de 22 departamentos do país para avaliar o conhecimento, aprovação e percepção da eficácia dos primeiros anos da Comissão a partir de aspectos psicossociais: vitimização, emoçóes colectivas, reconciliação, memória colectiva. Cinquenta e oito por cento foram vítimas directas. Os resultados 
indicam elevados níveis de aprovação e vontade de participar nas actividades da Comissão, bem como algum cepticismo quanto à sua utilidade e baixa confiança nas desculpas oficiais dos grupos em conflito. Há também um elevado nível de emoções positivas relacionadas com a comissão e uma baixa confiança nas instituiçóes governamentais. As conclusôes deste estudo coincidem com experiências anteriores de comissões de verdade na América Latina, e abrem o debate sobre as especificidades do contexto colombiano na busca da paz e as implicaçóes do trabalho da comissão no processo de reparação.

Palavras-chave: Comissão da Verdade da Colômbia, impacto psicossocial, justiça de transição, reparação às vítimas, reconciliaçáo social.

\section{Commission de la vérité colombienne: Connaissance, perception, efficacité et émotions associées.}

La Commission de la vérité en Colombie a été établie sur la base du modèle de justice transitionnelle. Sa fonction est de servir de mesure de reconnaissance des événements violents du conflit armé, qui ont fait plus de neuf millions de victimes. Dans ce cadre, une étude corrélationnelle descriptive $(N=1166)$ a été réalisée auprès d'un échantillon de 22 départements du pays pour évaluer la connaissance, l'approbation et l'efficacité perçue des premières années de la Commission sur la base des aspects psychosociaux : victimisation, émotions collectives, réconciliation, mémoire collective. Cinquante-huit pour cent étaient des victimes directes. Les résultats indiquent des niveaux élevés d'approbation et de volonté de participer aux activités de la Commission, ainsi qu'un certain scepticisme quant à son utilité et une faible confiance dans les excuses officielles des groupes en conflit. On constate également un niveau élevé d'émotions positives liées à la commission et une faible confiance dans les institutions gouvernementales. Les résultats de cette étude coïncident avec les expériences précédentes des commissions de vérité en Amérique latine, et ouvrent le débat sur les spécificités du contexte colombien dans la recherche de la paix et les implications du travail de la commission dans le processus de réparation.

Mots-clés: Commission Vérité Colombie, impact psychosocial, justice transitionnelle, réparation des victimes, réconciliation sociale. 
Para las sociedades que experimentan eventos de violencia política, se han propuesto buscar herramientas y procesos que favorezcan la reconstrucción del tejido social y que permitan disminuir los escenarios violentos para construir una cultura basada en la convivencia pacífica (Reyes et al., 2015; Arnoso et al., 2014; López-López, 2020; López-López et al., 2021). Estas sociedades que buscan transitar hacia escenarios en los que la gestión no violenta de los conflictos permita escenarios sostenibles de cuidado por la vida y el respeto a los derechos humanos; allí, uno de los mayores retos es enmarcar la justicia, la memoria colectiva y la forma de tratar los crímenes ocurridos en un contexto de confianza y no repetición.

En este contexto, dentro de los grupos protagonistas del conflicto y en la sociedad en general, existen múltiples posturas sobre cómo debe ser abordado el pasado de violencia, que se basan en las representaciones que se tienen sobre el pasado y el nivel de exposición a la violencia que ha experimentado cada grupo (Noor et al., 2015). Asimismo, la cercanía que se percibe con las víctimas directas, la posición ideológica y los intereses propios de cada grupo, generan polémica sobre cuáles son los procesos más adecuados para superar el pasado violento (Arnoso et al., 2015).

Una de las formas en las que este tipo de sociedades ha gestionado su pasado de violencia y los eventos traumáticos que han vivido se ha denominado justicia transicional. Este tipo de justicia se enfoca en procesos democratizadores de tránsito hacia la paz, haciendo posible la reparación de las víctimas y el juzgamiento de las violaciones a los Derechos Humanos (DDHH) (Hamber, 2007). En ese sentido, abarca los mecanismos jurídicos y no jurídicos — que utilizan acciones de justicia retributiva, con juicios y castigo a los responsables de las violaciones a los DDHH—, acciones de justicia restaurativa — como las peticiones de perdón públicas—, acciones de justicia distributiva para 
la reparación material, física y psicológica de las víctimas y acciones de justicia procedimental, como las Comisiones de la Verdad, enfocadas en el reconocimiento de los hechos violentos y la creación de una memoria histórica de lo sucedido (Arnoso et al., 2015).

El objetivo primario de los mecanismos de justicia transicional es la restauración y reparación de las víctimas, a través de instancias de disculpas oficiales, programas de reparación o esclarecimiento de los hechos, como es el caso de las Comisiones de la Verdad (CV) (Reyes et al., 2015). Estas comisiones, son organismos no judiciales que investigan las violaciones a los $\mathrm{DDHH}$ en el periodo de conflicto, con el fin de obtener una reconstrucción histórica de la memoria (Hamber, 2007).

\section{Comisiones de la Verdad en Latinoamérica}

Las CV se entienden como rituales transicionales para reforzar la cohesión social, donde su objetivo no es perseguir ni juzgar a los perpetradores (en la mayoría de los casos), sino crear recomendaciones para el periodo de posconflicto sobre la base de la verdad y contribuir a la prevención de nuevos ciclos de violencia colectiva desde el reconocimiento de las víctimas, la no impunidad y la identificación de patrones de victimización (Martín-Beristain et al., 2011). Apoyadas en el derecho a la verdad como mecanismos extrajudiciales, marcan la transición entre el pasado de violencia y los esfuerzos por construir una cultura basada en la convivencia pacífica.

Debido a que Latinoamérica ha experimentado diversos conflictos armados, dictaduras y repetidas violaciones a los DDHH durante el Siglo XX, muchos países de la región han utilizado el mecanismo de las CV para comprender la violencia colectiva y las dinámicas de los grupos involucrados e intentar superar los hechos traumáticos asociados. Se han llevado a cabo comisiones en Argentina, Chile, Ecuador, El Salvador, Paraguay, Perú, Uruguay, Brasil y, actualmente, en Colombia.; sus aportes, pueden ir desde informes detallados de la violencia en el país, la postulación de recomendaciones hacia el Estado, hasta aportar pruebas o juzgar, según el nivel de vinculación jurídica que cada país le 
otorga, a los grupos involucrados. En consecuencia, su alcance está relacionado con el entorno social en el cual se desarrolla, siendo variables como la confianza en la democracia y en las instituciones democráticas, el nivel de violencia previo y la favorabilidad del gobierno hacia sus conclusiones, elementos influyentes en su proceso (Arnoso et al., 2015; Mathias et al., 2020).

En general, se espera que estas comisiones beneficien a la sociedad estableciendo una memoria colectiva basada en la verdad sobre el pasado, pero también posibilitando recopilar información sobre las personas desaparecidas, los responsables de las violaciones a los DDHH y los grupos que directa o indirectamente posibilitaron o colaboraron en el mantenimiento de la violencia. Por otra parte, deben motivar a los gobiernos para generar reparaciones económicas y simbólicas desde el reconocimiento de la verdad, que en estos contextos ha sido silenciada, negada o modificada desde los intereses políticos y económicos de los perpetradores (Arnoso et al., 2015).

Los informes creados por las comisiones, se constituyen como un instrumento de protección de los $\mathrm{DDHH}$, que pueden crear una conciencia colectiva que previene futuros enfrentamientos y nuevos tipos de violencias (Martin-Beristaín et al., 2011). No obstante, esta creación de memoria histórica atraviesa las representaciones del pasado, que en muchas ocasiones pueden ser contradictorias dependiendo de las posiciones ideológicas y el nivel de victimización sufrido (Páez y Liu, 2011). Se ha encontrado consistentemente que, en países latinoamericanos con una historia de violencia principalmente estatal (dictaduras), las víctimas suelen ser más favorables a revisar el pasado aun cuando el coste emocional de revivir las historias traumáticas sea elevado. Asimismo, las personas que se definen ideológicamente en la derecha política, suelen restar importancia a los hechos ocurridos siendo más desfavorables a iniciativas de memoria (Arnoso et al., 2015), sin embargo, en casos donde la victimización no proviene únicamente del Estado, como es el caso peruano, la victimización resulta ser una variable de suma importancia y los resultados a partir de la posición política, pueden variar (Espinosa et al., 2017). 
En Latinoamérica, la visión positiva del clima socioemocional, está asociado con la visión positiva del trabajo de la $\mathrm{CV}$, lo que sugiere que este mecanismo, incrementa la cohesión social a largo plazo (Mathias, 2020). Por lo general, en Argentina, Chile, Paraguay hay o hubo actitudes más favorables hacia la Comisión mientras que, en Bolivia y El Salvador, la favorabilidad es más reducida, mientras que, en Perú, aunque hubo una actitud favorable, la opinión estuvo muy divida. Esta favorabilidad puede estar relacionada con los resultados y las consecuencias derivadas del trabajo de la comisión. En Argentina y en Chile, por ejemplo, se generaron informes y se llevaron a cabo juicios y peticiones públicas de disculpas, en Paraguay, además algunas medidas de reparación. Por el contrario, en El Salvador los reportes fueron poco publicitados y desmeritados por el gobierno y en Bolivia no se generó ningún reporte. En el caso peruano, aunque hubo reportes y juicios, estos fueron limitados y no lograron satisfacer a las víctimas. En todos los países, se ha evidenciado una actitud crítica hacia el ofrecimiento de disculpas de los grupos perpetradores, ya que no se perciben como sinceras ni beneficiosas para la confianza entre los grupos (Mathias, 2020; Arnoso et al., 2014).

Se ha encontrado que hay un desconocimiento importante del trabajo de las comisiones realizadas, siendo Argentina y Uruguay los países con mayor conocimiento. Por último, como tendencia para todos los países, excepto para Perú, se ha relacionado una mayor exposición a la violencia y la posición ideológica de izquierdas con mayor conocimiento de la comisión, en gran parte debido a que, en la mayoría de los países, la violencia política ha sido ejercida por dictaduras de extrema derecha. La eficacia de las comisiones ha sido medida también en estos países y se ha encontrado que el $46.2 \%$ de las personas las considera eficaces (Arnoso et al., 2015).

\section{El posacuerdo de paz y la Comisión de la Verdad en Colombia}

En Colombia, la violencia colectiva se enmarca en un conflicto armado interno que lleva activo más de 60 años y que ha dejado hasta finales de 2020, más de nueve millones de víctimas (Registro Único 
de Víctimas, 2020). Diferentes grupos guerrilleros, paramilitares y cárteles de narcotráfico han propiciado, junto con las fuerzas armadas del Estado, situaciones de desplazamiento, desapariciones, secuestros y masacres que han dejado al país en el centro de una de las mayores crisis humanitarias de la historia moderna (Trejos, 2013).

Luego del periodo de mayor victimización y acciones violentas, entre finales de los años 90 y la primera década de los 2000, el país comienza una etapa de negociaciones de paz con la guerrilla de las FARC-EP (Fuerzas Armadas Revolucionarias de Colombia - Ejército del Pueblo), la más grande y antigua del país. Estas negociaciones, dan como resultado la firma del acuerdo de paz del 2016 con el cual dicha guerrilla se desmoviliza, y se crean acuerdos con el Estado, que incluyen reformas agrarias, inclusión política, así como la creación de un modelo de justicia transicional para tratar los hechos relacionados con el conflicto armado (Jurisdicción Especial para la Paz, 2019).

Uno de los puntos tratados dentro del acuerdo de paz, fue la creación del Sistema Integral de Verdad, Justicia, Reparación y no Repetición, el cual está integrado por tres instituciones que buscan esclarecer los hechos relacionados con el conflicto, juzgar a los responsables y reparar a las víctimas a través de medidas y mecanismos judiciales y extrajudiciales. Estas instituciones son: la Jurisdicción Especial para la Paz, el órgano jurídico por medio del cual se investiga y juzga a los actores armados y civiles que hayan tenido alguna responsabilidad durante el conflicto; la Unidad de Búsqueda para Personas dadas por Desparecidas, que tiene la tarea de rastrear a las personas declaradas desaparecidas durante los años y a razón del conflicto; la Comisión para el Esclarecimiento de la Verdad, la Convivencia y la No Repetición, un ente autónomo de orden nacional que busca la verdad sobre lo ocurrido en el conflicto armado con el fin de promover el reconocimiento de las víctimas y el esclarecimiento de los hechos (Jurisdicción Especial para la Paz, 2019).

Esta Comisión, como entidad temporal e independiente, tiene un mandato de tres años a partir de su creación a finales del año 2018, para investigar las graves violaciones a los DDHH durante el conflicto, 
así como identificar los patrones de violencia para encontrar las causas del inicio y mantenimiento de la violencia en el país (Martín-Beristain, 2016). En ella, las víctimas, los perpetradores y la sociedad en general son llamados a compartir sus experiencias, y la información sobre los hechos violentos para lograr, con la ayuda de los registros oficiales, revisión bibliográfica histórica y documentos militares y estatales, crear una verdad histórica que reivindique la dignidad de las víctimas.

La comisión, tiene como objetivos principales: 1. Contribuir al esclarecimiento de la verdad sobre el conflicto, buscando ofrecer una explicación desde la complejidad para comprender lo ocurrido. 2. Promover el reconocimiento de las víctimas, así como de sus afectaciones y las violaciones a los DDHH y 3. Promover la convivencia en los territorios para buscar la reconciliación social (Jurisdicción Especial para la Paz, 2019). Es importante aclarar, que esta Comisión no tiene un carácter vinculante jurídicamente, es decir, dentro de sus funciones no está la de realizar juicios, ni tiene potestad para juzgar o establecer penas a los responsables. Por el contrario, como otras comisiones, busca encontrar los patrones de victimización y los grupos que realizaron actos violentos o que permitieron, financiaron o apoyaron estas dinámicas. Su prioridad, será la búsqueda de una cohesión social y el reconocimiento de las víctimas (Martín-Beristain, 2016; Cárdenas et al., 2013).

Al terminar su mandato oficial, la Comisión deberá entregar un informe detallado sobre sus investigaciones y las conclusiones a las que haya llegado, generando recomendaciones al Estado, orientadas a la verdad, la justicia y la reparación de las víctimas con el fin de crear políticas, leyes y nuevas herramientas que ayuden al país a superar la violencia colectiva vivida. Tal y como se ha hecho en otros países Latinoamericanos, será de vital importancia medir el impacto que tenga esta comisión, no solo en las víctimas y los perpetradores, sino en la sociedad en general, así como conocer las percepciones de la población, frente al cumplimiento de sus objetivos y su utilidad para el conjunto de los grupos afectados.

En ese marco, se crea en Colombia la Red de Investigación Sobre la Verdad en el Conflicto Armado Colombiano (en adelante Red IVCAC), 
conformada por 23 investigadores de 17 universidades del país y del Grupo Consolidado de Investigación Cultura, Cognición y Emoción de la Universidad del País Vasco - España, con el propósito de conocer el impacto psicosocial de la Comisión de la Verdad en Colombia en la población víctima, los perpetradores y la población civil no víctima en 22 departamentos, repartidos en las seis regiones administrativas de Colombia contempladas por el Departamento Nacional de Planeación (Departamento Nacional de Planeación, 2017).

Actualmente, aún con la firma del acuerdo de paz y la desmovilización de la guerrilla de las FARC-EP en 2016, el país sufre de graves eventos de violencia colectiva entre grupos paramilitares, narcotraficantes, otras guerrillas y disidencias de las FARC. Sumado a esto, cuatro años después de la firma del acuerdo, este no se cumple en su totalidad y tiene graves retrasos en sus puntos fundamentales debido a la falta de compromiso por parte del gobierno, lo que ha aumentado la reactivación de la violencia y ha agravado la situación de los reinsertados y líderes sociales, que para 2020, sumaban más de 600 asesinados en todo el país.

\section{Método}

\section{Participantes}

Se diseñó un estudio transversal de tipo descriptivo correlacional. La muestra total fue de 1166 personas y el rango de edad de los participantes estuvo entre los 18 y los 80 años. El 51,1\% eran estudiantes universitarios y más de la mitad de la muestra fueron mujeres (Ver Tabla 1). 


\section{Tabla 1}

Características demográficas de la muestra

\begin{tabular}{lccccccc}
\hline & $\begin{array}{c}\text { Muestra } \\
\text { Total }\end{array}$ & Caribe & $\begin{array}{c}\text { Centro } \\
\text { Oriente }\end{array}$ & $\begin{array}{c}\text { Centro } \\
\text { Sur }\end{array}$ & $\begin{array}{c}\text { Eje } \\
\text { Cafetero* }\end{array}$ & $\begin{array}{c}\text { Llanos } \\
\text { Orientales }\end{array}$ & Pacífico \\
\hline Edad: & 26.91 & 23.04 & 25.15 & 23.01 & 44.29 & 36.81 & 25.86 \\
$M(D T)$ & $(11.07)$ & $(8.65)$ & $(8.39)$ & $(6.51)$ & $(20.79)$ & $(14.00)$ & $(8.91)$ \\
Género & & & & & & & \\
Femenino & $64.2 \%$ & $66.9 \%$ & $59.9 \%$ & $48.4 \%$ & $42.9 \%$ & $59.3 \%$ & $77.6 \%$ \\
Masculino & $35.8 \%$ & $33.1 \%$ & $40.1 \%$ & $51.6 \%$ & $57.1 \%$ & $40.7 \%$ & $22.4 \%$ \\
Educación & & & & & & & \\
Alta & $53 \%$ & $60.8 \%$ & $57.6 \%$ & $74.2 \%$ & $57.1 \%$ & $27.0 \%$ & $50.8 \%$ \\
Media & $41.1 \%$ & $36.5 \%$ & $39.5 \%$ & $24.2 \%$ & $0 \%$ & $54.9 \%$ & $46.9 \%$ \\
Baja & $5.7 \%$ & $2.7 \%$ & $2.8 \%$ & $1.6 \%$ & $42.9 \%$ & $18.1 \%$ & $2.3 \%$ \\
Posición política & & & & & & \\
Izquierda & $39.5 \%$ & $28.8 \%$ & $42.1 \%$ & $62.1 \%$ & $28.6 \%$ & $26.1 \%$ & $43.8 \%$ \\
Centro & $45.6 \%$ & $57.7 \%$ & $49.4 \%$ & $34.6 \%$ & $42.9 \%$ & $43.4 \%$ & $41.5 \%$ \\
Derecha & $14.8 \%$ & $13.5 \%$ & $8.4 \%$ & $3.3 \%$ & $28.6 \%$ & $30.5 \%$ & $14.7 \%$ \\
N & 1166 & 260 & 178 & 182 & 7 & 226 & 313 \\
\hline
\end{tabular}

Nota: $N=1166$. Se reporta el porcentaje (\%) válido. Educación: Dicotomizada a partir de cuatro niveles $($ Alta $=$ Universitaria y posgrado, Media $=$ Secundaria, Técnica y Tecnológica, Baja $=$ No escolarizado y Básica Primaria). Posición política: Categorización de una escala continua $1-5$ (Izquierda $=1$ y 2, Centro= 3, Derecha $=4$ y 5). ${ }^{*}$ Los porcentajes se dan de forma ilustrativa, ya que con tan pocos participantes estos tienen un sentido muy limitado.

En general, hay mayor porcentaje de mujeres, de participantes con un nivel de educación media y predominantemente de centro y de izquierda. La tabla 2 muestra los porcentajes totales y por región con respecto a la victimización -si el participante fue víctima-

El porcentaje de victimización es mayor al $50 \%$ en todos los casos excepto en el Centro Oriente. Por otro lado, en todos los casos, al menos el $60 \%$ de los participantes reportan tener familiares en alguna de las fuerzas armadas del estado - exceptuando el Eje Cafetero- y un porcentaje nunca superior al 20\% para familiares en grupos armados 
ilegales. Debido al limitado tamaño muestral de la región del Eje Cafetero, estos datos no se utilizan en el análisis de resultados.

\section{Tabla 2}

Porcentajes totales y por región de victimización y cercanía con los grupos armados.

\begin{tabular}{lcccccc}
\hline & & \multicolumn{5}{c}{ Grupo armado } \\
\cline { 3 - 7 } \multicolumn{1}{c}{ Región } & Victimas & Guerrillas & Paramilitares & Múltiple & $\begin{array}{c}\text { Bandas } \\
\text { criminales }\end{array}$ & $\begin{array}{c}\text { Fuerzas } \\
\text { Armadas }\end{array}$ \\
\hline Caribe & $57.7 \%$ & $32.8 \%$ & $18.7 \%$ & $29.1 \%$ & $3.8 \%$ & $1.5 \%$ \\
Centro Oriente & $44.9 \%$ & $50.7 \%$ & $11.6 \%$ & $27.5 \%$ & $4.3 \%$ & $1.4 \%$ \\
Centro Sur & $53.3 \%$ & $55.3 \%$ & $16.5 \%$ & $22.4 \%$ & $1.2 \%$ & $2.4 \%$ \\
Eje Cafetero & $71.4 \%$ & $0 \%$ & $50 \%$ & $50 \%$ & $0 \%$ & $0 \%$ \\
Llanos Orientales & $67.3 \%$ & $55.6 \%$ & $17.4 \%$ & $19.4 \%$ & $2.1 \%$ & $4.2 \%$ \\
Pacífico & $62 . \%$ & $50.2 \%$ & $9.2 \%$ & $19 \%$ & $15.5 \%$ & $1.4 \%$ \\
Total & $58.1 \%$ & $47.9 \%$ & $15.1 \%$ & $23.2 \%$ & $8.8 \%$ & $2.2 \%$ \\
\hline
\end{tabular}

Nota: $N=1166$. Se reporta el porcentaje (\%) válido. Fuerzas Armadas = Fuerzas Militares, Fuerza Aérea, Fuerza Naval; Múltiple $=$ Guerrillas, Paramilitares y Fuerzas Armadas.

\section{Procedimiento}

Se contactó con profesores e investigadores de múltiples universidades en 22 departamentos del país para la creación de la Red IVAC. Se realizó una adaptación del instrumento utilizado previamente (Arnoso et al., 2007; Bombelli et al., 2013; Cardenas et al, 2013; Arnoso et al., 2014; Reyes et al, 2015; Arnoso et al., 2015; Espinosa et al, 2017) sobre las Comisiones de la Verdad en Latinoamérica al contexto colombiano y se preparó por medio de la plataforma de Google Forms, para su aplicación virtual y un cuestionario en papel con las mismas preguntas para las zonas del país con problemas de accesibilidad. Posteriormente, todos los miembros de la Red fueron entrenados en la aplicación del instrumento para hacer el estudio piloto en 12 departamentos del país con un promedio de dos sujetos por cada 
departamento; posteriormente, se inició la recolección de datos entre enero de 2020 y enero de 2021. El tiempo de duración de la aplicación varió entre 35 y 50 minutos dependiendo de la región y la forma de aplicación; el instrumento fue aplicado siempre por un miembro de la Red por medio de un ordenador o la versión impresa. Para las aplicaciones impresas, el miembro de la red encargado depositaba los datos en la base de datos virtual. El procedimiento de recolección de datos fue similar en todas las regiones; se utilizó la recolección por conveniencia en todas las zonas. Todos los participantes leyeron y aceptaron el consentimiento informado y la participación fue voluntaria y anónima por medio de la asignación de claves numéricas.

\section{Instrumento}

Los participantes contestaron al cuestionario descrito a continuación:

- Información sociodemográfica: preguntas sobre la edad, género, ciudad y departamento de residencia, grupo étnico.

- Ideología política: única pregunta ad hoc, con cinco posibles opciones de respuesta desde $1=$ Extrema izquierda hasta $5=$ Extrema derecha. "A menudo, cuando la gente habla de temas politicos, utiliza términos como "de derecha" o "de izquierda" para describir sus puntos de vista. ¿Cómo se definiría a si mismo según estos términos?"

- Exposición a la violencia: lista de diez sucesos violentos (e.g., pérdida de trabajo, secuestro, agresión, desplazamiento etc.). Adicionalmente se preguntó por el grupo armado que realizó el hecho.

- Conocimiento sobre la Comisión: una escala de 1= "Ninguna" a 6 = "Muchísima", cuanta información poseía sobre la Comisión de la verdad y sus objetivos. Luego de esta pregunta, los participantes leyeron un enunciado de información básica sobre la Comisión. 
- Aprobación de la comisión: en una escala de 1 = "Lo desaprueba firmemente" a 4 = "Lo aprueba firmemente", se preguntó: "Con respecto a lo que la comisión va a hacer. Usted:".

- Conocimiento y participación en actividades relacionadas con la Comisión: ocho ítems relacionados con si han visto o escuchado información sobre la Comisión en diferentes medios de comunicación. Además, cuatro ítems sobre la participación en actividades simbólicas de víctimas (e.g., Ha participado en actividades simbólicas de recuerdo de las victimas (concentraciones, marchas, movilizaciones no religiosas). Por último, cuatro ítems sobre disposición a participar en actividades de la Comisión. Se preguntó a los participantes por medio de una escala de $1=$ "Nada" a 4 = "Mucho". $(\alpha=.83)$.

- Efectividad percibida de la comisión: se pidió a los participantes que evaluaran en una escala de 1 = "Nada"/ 4 = "Mucho", una lista de siete enunciados referentes a la consecución de los objetivos de la comisión a futuro (e.g. Ayudará a las familias de las victimas a saber lo que ocurrió a sus seres querido o Ayudará a que se coexistan en paz los diferentes actores de la violencia y que mejore la convivencia entre colombianos) $(\alpha=.89)$.

- Disculpas de los grupos en conflicto: conocimiento de las disculpas públicas pronunciadas por Juan Manuel Santos (presidente de Colombia durante la época del acuerdo de paz), dirigentes de las FACR-EP, dirigentes de las AUC, dirigentes de las Fuerzas Militares (Sí/No). Se aplicó la escala de disculpas (Reyes et al., 20150), para medir la sinceridad de las disculpas percibidas a cada grupo $(\alpha=.72)$, la utilidad para comprender el sufrimiento de las víctimas $(\alpha=.80)$ y la utilidad para promover la confianza entre los grupos en conflicto $(\alpha=.83)$, con una escala de 1 = "Nada" a 4 = "Mucho".

- Confianza institucional: por medio de una lista de seis instituciones gubernamentales (poder legislativo, poder ejecutivo, 
poder judicial, gobiernos departamentales, gobiernos locales, partidos políticos) y seis instituciones no gubernamentales (sindicatos, ONG, Comisión de la Verdad, Jurisdicción Especial para la Paz, líderes sociales y universidades). Se les preguntó a los participantes el nivel de confianza en cada una de ellas en una escala de 1 = "No confía" a 4 = "Mucha confianza". Se realizó un análisis factorial de componentes principales $\left(\mathrm{KMO}=.79\right.$, Bartlett $\left.X^{2}(66)=237.45 p=<.001\right)$ con rotación Varimax forzando dos factores que explican el $57.1 \%$ de la varianza. El primer factor, compuesto por las instituciones gubernamentales, explica el $36.3 \%$ de la varianza $(\alpha=.83)$ y el segundo, el $49.7 \%(\alpha=.85)$.

- Compartir social: Item único adaptado de la escala de Rimé (2012), enfocado en la Comisión de la Verdad $\left({ }_{¡} H a\right.$ hablado acerca de Comisión de la Verdad con otras personas durante el último mes?).

- Emociones asociadas al trabajo futuro de la Comisión: los participantes evaluaron en una escala de 1 = "Nada" a 4 = "Mucho", cuatro emociones positivas $(\alpha=.79)$ y ocho emociones negativas $(\alpha=.88)$ referentes al trabajo que realizará la Comisión. Adicionalmente se preguntó por cuatro emociones de trascendencia (Cusi et al. 2018) ( $\alpha=.65)$. (e.g. Cuando piensa en la actividad que ha realizado o realizará la Comisión de la Verdad en relación con las víctimas usted siente: Tristeza, dolor Infelicidad; Culpa arrepentimiento, culpabilidad).

- Reconciliación Social: Adaptación de la escala de Wohl y Branscombre, (2005) con la pregunta "¿Que sería necesario para la reconciliación entre las víctimas y los que les causaron daños?" y ocho afirmaciones con los aspectos necesarios para la reconciliación "Que los victimarios pidan perdón con sinceridad” en una escala de 1 = "Nada" a 4 = "Mucho", $(\alpha=.85)$. 
- Actitudes hacia el recuerdo: dos ítems con afirmaciones acordes con una actitud a favor del recuerdo de los eventos violentos (Se midió indirectamente por medio de la disposición a aprender del pasado) "Cuando se trata del pasado de Colombia durante el conflicto armado, debemos aprender de los errores que se hicieron con el fin de evitar cometer los mismos errores nuevamente" y una actitud a favor del olvido "Es mejor que no se abran viejas heridas hablando de lo que sucedió en el pasado por el conflicto armado" con una escala de 1 = "Totalmente falsa" a 4 = "Totalmente verdadera".

\section{Análisis de datos}

El análisis de datos se realizó mediante el paquete estadístico SPSS 26. Se realizan análisis descriptivos y análisis de fiabilidad de todas las escalas por medio del coeficiente Alfa de Cronbach (Ver tabla 3). Posteriormente se hacen comparaciones entre grupos y análisis de varianza de acuerdo al nivel de exposición a la violencia y variables de conocimiento de la comisión. Por último, se realizan comparaciones post hoc, incluyendo cálculos de tamaño del efecto.

\section{Resultados}

Las puntuaciones medias de las escalas utilizadas, así como el coeficiente de confiabilidad, asimetría y curtosis se muestran en la Tabla 3. La muestra presenta índices de asimetría inferiores a 1, excepto en las emociones negativas y la autoestima colectiva, y curtosis inferiores a 1 excepto en la confianza en instituciones gubernamentales. Se aplica el estadístico $\mathrm{F}$ que ha mostrado ser robusto para igual o inferiores asimetrías y curtosis \pm 1 (Blanca et al., 2017). Todos los coeficientes de fiabilidad alfa de Cronbach fueron aceptables con valores por encima de .79 . 


\section{Tabla 3}

Estadisticos descriptivos, Coeficiente de Confiabilidad ( $\alpha$ Cronbach) y Coeficientes Omega (w)

\begin{tabular}{|c|c|c|c|c|c|c|c|c|}
\hline Escalas No ítems & & $\alpha$ & $w$ & $\begin{array}{l}\text { Míni- } \\
\text { mo }\end{array}$ & $\begin{array}{l}\text { Máxi- } \\
\text { mo }\end{array}$ & $M(D E)$ & $\begin{array}{l}\text { Asime- } \\
\text { tría }\end{array}$ & $\begin{array}{l}\text { Curto- } \\
\text { sis }\end{array}$ \\
\hline $\begin{array}{l}\text { Efectividad de la } \\
\text { comisión }\end{array}$ & 7 & .93 & .93 & 1.0 & 4.0 & $2.74(.80)$ & -.270 & -.600 \\
\hline Compartir Social & 1 & - & & 1.0 & 4.0 & $1.47(.77)$ & - & - \\
\hline $\begin{array}{l}\text { Emociones asociadas a } \\
\text { la Comisión }\end{array}$ & 16 & & & & & & & \\
\hline Emociones negativas & 8 & .88 & .88 & 1.0 & 4.0 & $1.59(.63)$ & 1.180 & .986 \\
\hline Emociones positivas & 4 & .86 & .87 & 1.0 & 4.0 & $2.16(.93)$ & .376 & -.893 \\
\hline $\begin{array}{l}\text { Emociones de } \\
\text { trascendencia }\end{array}$ & 4 & .83 & .84 & 1.0 & 4.0 & $2.01(.81)$ & .533 & -.501 \\
\hline Reconciliación social & 8 & .83 & .84 & 1.0 & 4.0 & $2.87(.69)$ & -.629 & -.084 \\
\hline $\begin{array}{l}\text { Confianza } \\
\text { gubernamental }\end{array}$ & 6 & .89 & .89 & 1.0 & 4.0 & $1.62(.54)$ & .898 & 1.104 \\
\hline $\begin{array}{l}\text { Confianza no } \\
\text { gubernamental }\end{array}$ & 6 & .85 & .85 & 1.0 & 4.0 & $2.40(.69)$ & -.073 & -.383 \\
\hline
\end{tabular}

\section{Exposición a la violencia, conocimiento y aprobación del trabajo de la Comisión}

En total, el $58.1 \%$ de los participantes eran víctimas directas. Se observan diferencias significativas en cuanto a la edad entre el grupo de víctimas $(M=28.49$ años, $D E=12.10)$ en relación con el grupo de no victimas $(M=24.72$ años, $D E=9.03)[F(55,1110)=1.440 ; p=$ $.021 ; \eta 2=.067]$. Igualmente, hay una mayor cantidad de mujeres víctimas (64.2\%). Entre la población víctima, los actos de violencia más reportados son: desplazamiento forzado (31.3\%), amenazas y extorciones $(28.9 \%)$, asesinato de un familiar $(27.1 \%)$, pérdida de trabajo (25.1\%) y despojo de tierras (24.4\%), los grupos perpetradores por cada región se indican en la tabla 2. 
El 69.4\% de los participantes reportan tener poco o ningún conocimiento sobre la comisión de la verdad y sus objetivos. Aun cuando en general, los puntajes medios del conocimiento de la comisión es bajo, se encontraron diferencias estadísticamente significativas por región $[F(5.1160)=3.275 ; p=.006 \eta 2=.014]$, género $[F(1.1162)=$ $4.185 ; p=.041 \eta 2=.004]$ y victimización $[F(1.1164)=7.555 ; p=.006$ $\eta 2=.006]$; no se encontraron diferencias significativas en cuanto a la posición política, aún cuando la media de las personas de izquierda es mayor que el resto; tampoco se encontraron diferencias en relación con la edad de los participantes. Las diferencias por específicas pueden observarse en la tabla 4.

En cuanto a las diferencias por género, los hombres $(M=2.14$ $D E=.90)$ reportaron mayor conocimiento que las mujeres $(\mathrm{M}=2.03$ $D E=.90)$ y las víctimas $(\mathrm{M}=2.13 D E=.90)$, mayor conocimiento que la población no víctima $(M=1.98 D E=.90)$; por último, los medios de información desde los cuales los participantes han escuchado sobre la comisión son principalmente la televisión $(M=2.08 D E=0.86)$ y las redes sociales $(M=2.08 D E=1.00)$, y en menor medida en los periódicos $(M=1.80 D E=0.89)$ y la radio $(M=1.78 D E=0.88)$.

\section{Tabla 4}

Diferencias entre regiones en las variables de conocimiento y aprobación de la Comisión

\begin{tabular}{lccccccccc}
\hline & \multicolumn{8}{c}{ Región } & \\
\cline { 2 - 7 } Variables & Caribe & Centro & Centro & Llanos & Pacífico & & & $\eta^{2}$ \\
& $M(D E)$ & Oriente & Sur & Orientales & & \\
& $M(D E)$ & $M(D E)$ & $M(D E)$ & $M(D E)$ & $F$ & $p$ & \\
\hline Conocimiento & $2.09^{\mathrm{b}}$ & 2.01 & $2.19^{\mathrm{b}}$ & $2.19^{\mathrm{b}}$ & $1.94^{\mathrm{a}}$ & 3.275 & .006 & .014 \\
CV & $(.92)$ & $(.87)$ & $(.91)$ & $(1.02)$ & $(.79)$ & & & \\
Aprobación & $2.97^{\mathrm{a}}$ & $2.72^{\mathrm{b}}$ & $3.14^{\mathrm{bc}}$ & $2.58^{\mathrm{bd}}$ & $2.65^{\mathrm{bd}}$ & 13.317 & .000 & .054 \\
CV & $(.79)$ & $(.81)$ & $(.81)$ & $(.89)$ & $(.85)$ & & & \\
\hline
\end{tabular}

Nota: Diferentes letras indican diferencias estadísticamente significativas (post-hoc DMS) $(p<.05)$ 
A pesar de que solo un $30.6 \%$ de los participantes dice tener información sobre la comisión, el 65\% de los participantes aprueba su trabajo. Comparando con los resultados de las encuestas en otros siete países sudamericanos, se comprueba que el nivel de conocimiento es el menor de todos mientras que el de aprobación se sitúa en la media, siendo en general, alta (ver Tabla 5).

Se encontraron diferencias estadísticamente significativas en la aprobación del trabajo de la comisión con relación a la región de los participantes, con un tamaño del efecto medio-alto $[F(5,1160)=13.317$; $p=.0001 ; \eta 2=.054]$, siendo el Centro Sur y los Llanos Orientales los que reportan mayor conocimiento y la región Caribe la mayor aprobación (Ver tabla 4). También, la media de aprobación de los participantes varía en función de su posición política significativamente $[F(2.1163)$ $=19.261 ; p=.0001 ; \eta 2=.032]$, siendo aquellos que se identifican con la posición de izquierda, los que tienen mayor aprobación $(M=2.98$; $D E=.87)$, en comparación con las personas que indicaron ser de centro $(M=2.69 ; D E=.80 ; p=.000)$ y de derecha $(M=2.63 ; D E=.88 ; p=.000)$. No se encontraron diferencias en cuanto al género o la victimización.

\section{Participación en actividades y efectividad percibida de la Comisión}

Los participantes reportaron puntuaciones bajas de participación en actividades y rituales simbólicos en relación con las víctimas del conflicto con anterioridad al trabajo de la comisión $(M=1.57 \mathrm{DT}$ $=.68)$, sin embargo, el $75.7 \%$ estaría dispuesto a prestar colaboración a la Comisión y el $66.4 \%$ a asistir a las audiencias públicas que se realicen. Tanto para la colaboración con la Comisión $[F(5,1160)=$ $10.601 ; p=.007 ; \eta 2=.014]$, como para disposición a asistir a audiencias públicas $[F(5,1160)=10.601 ; p=.0001 ; \eta 2=.044]$, el porcentaje varía significativamente con respecto a la región, siendo los Llanos Orientales y el Pacífico, las regiones como mayor disposición en ambos casos.

Para la efectividad se sumaron los puntajes de percepción de la consecución de todos los objetivos de la comisión. La tabla 5 muestra los cuatro objetivos generales de la comisión en comparación con otros siete países de Latinoamérica. Colombia mantiene para todos los obje- 
tivos porcentajes por encima del 50\%; estos porcentajes, son además superiores a la muestra de Uruguay, Brasil, Chile, Ecuador y Perú, siendo este último el de porcentajes más bajos con respecto a lo que los participantes consideran que la comisión puede lograr. Por último, siguiendo la tendencia de los otros siete países, las actitudes hacia recordar el pasado y aprender de él son altas, mientras que las actitudes hacia olvidar lo ocurrido son bajas.

Tanto la muestra general colombiana como todas las regiones del país mostraron puntajes superiores a la media de la escala, lo que indica una percepción alta de efectividad sobre el trabajo que realizará la comisión. No se encontraron diferencias significativas en esta variable con respecto a la edad, el género, la victimización o la posición política.

\section{Tabla 5}

Conocimiento, aprobación, acuerdo con objetivos CV y actitudes hacia el recuerdo por pais*.

\begin{tabular}{lcccccccc}
\hline & $\begin{array}{c}\text { Colom- } \\
\text { bia }\end{array}$ & $\begin{array}{c}\text { Argen- } \\
\text { tina }\end{array}$ & Brasil & Chile & $\begin{array}{c}\text { Ecua- } \\
\text { dor }\end{array}$ & $\begin{array}{c}\text { Para- } \\
\text { guay }\end{array}$ & Perú & $\begin{array}{c}\text { Uru- } \\
\text { guay }\end{array}$ \\
\hline Conocimiento CV & $31 \%$ & $90 \%$ & $52 \%$ & $49 \%$ & $49 \%$ & $45 \%$ & $48 \%$ & $91 \%$ \\
Aprobación CV & $65 \%$ & $92 \%$ & $76 \%$ & $62 \%$ & $67 \%$ & $98 \%$ & $61 \%$ & $61 \%$ \\
Objetivos de la Comisión & & & & & & & \\
Conocer lo ocurrido & $65 \%$ & $83 \%$ & $60 \%$ & $51 \%$ & $46 \%$ & $71 \%$ & $24 \%$ & $15 \%$ \\
Crear historia & $59 \%$ & $71 \%$ & $40 \%$ & $33 \%$ & $49 \%$ & $61 \%$ & $23 \%$ & $32 \%$ \\
integradora & & & & & & & & \\
Juzgar a culpables & $57 \%$ & $84 \%$ & - & $37 \%$ & $29 \%$ & $43 \%$ & $26 \%$ & $30 \%$ \\
No repetición & $53 \%$ & $72 \%$ & $46 \%$ & $37 \%$ & $38 \%$ & $61 \%$ & $22 \%$ & $33 \%$ \\
Actitudes hacia el recuerdo de los hechos violentos & & & & & \\
Recordar & $80 \%$ & $92 \%$ & $89 \%$ & $86 \%$ & $83 \%$ & $92 \%$ & $91 \%$ & $42 \%$ \\
Olvidar & $34 \%$ & $21 \%$ & $18 \%$ & $33 \%$ & $33 \%$ & $5 \%$ & $51 \%$ & $33 \%$ \\
\hline
\end{tabular}

Nota: Los porcentajes reflejan el porcentaje total de respuestas situadas en el rango de 3 y 4 de las escalas. Los porcentajes han sido extraídos de las bases de datos de los siete estudios (ver artículos citados) y Mathias et al., 2020.* 
Además de estos cuatro objetivos, se les preguntó a los participantes si creen que la Comisión ayudará a considerar la experiencia de las víctimas, para lo cual, el 60\% contestó afirmativamente (respondiendo en el rango de 3 y 4 de la escala). Por último, el 58\% también considera que la comisión puede ayudar a que los diferentes actores armados convivan pacíficamente entre ellos y los colombianos.

\section{Disculpas oficiales y confianza institucional}

El nivel de conocimiento sobre las disculpas oficiales de los participantes fue generalmente bajo, siendo el conocimiento de disculpas de las FARC-EP el más alto. Los resultados para cada uno pueden observarse en la figura 1.

\section{Conocimiento Disculpas Oficiales}

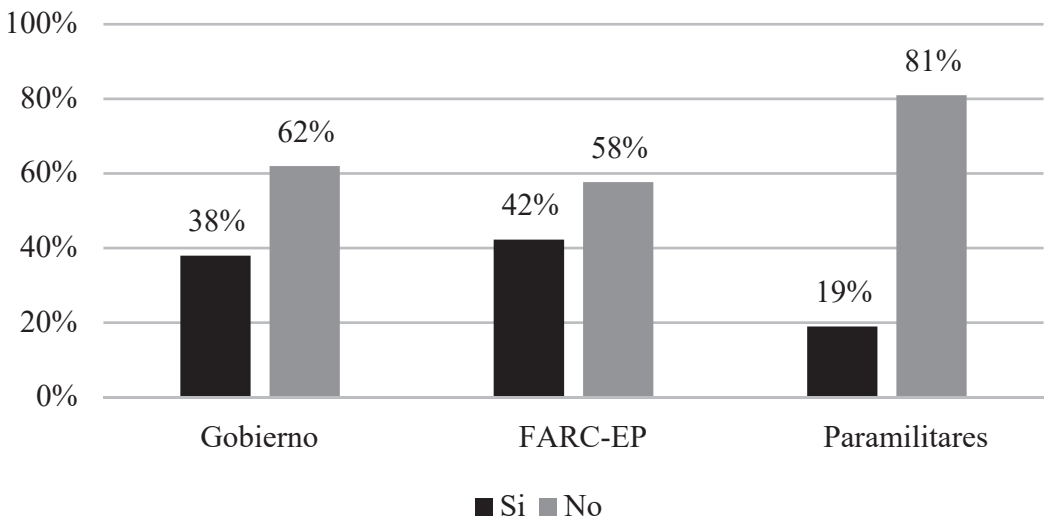

Figura 1. Porcentaje de conocimiento de las disculpas oficiales de los grupos perpetradores.

Asimismo, la sinceridad percibida en las disculpas solo superó la media teórica en el caso del gobierno de Juan Manuel Santos y solo en el caso de dicho gobierno y de las FARC-EP, consideran que esas disculpas pueden ser de ayuda para mejorar las relaciones entre los grupos en 
conflicto (Ver figura 2). La percepción media de sinceridad de las disculpas gubernamentales en los otros siete países de Latinoamérica fue del $24 \%$ en otros estudios, frente a un $19 \%$ en Colombia; igualmente, la utilidad de dichas disculpas se sitúa en un $14 \%$, frente a un $24 \%$ en los demás países y un $15 \%$ considera que ayudan a mejorar la relación de los grupos en conflicto en Colombia, y un 16\% como media de los demás países (Mathias, 2020).

Aspectos de las Disculpas por Grupo

3

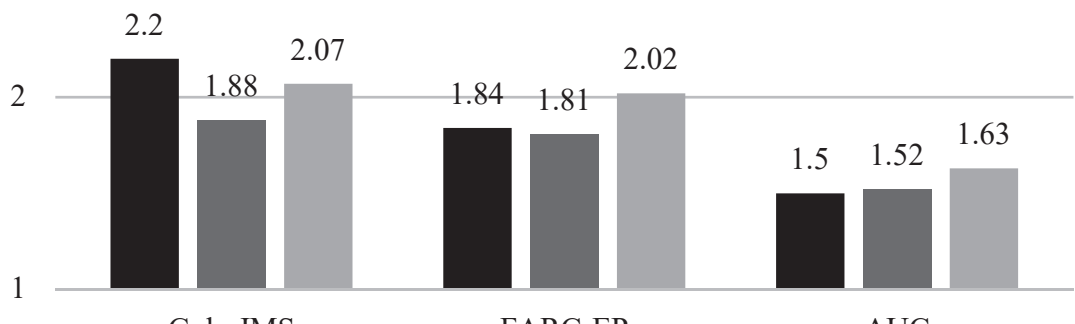

Gob. JMS

FARC-EP

AUC

- Sinceridad Utilidad para las víctimas Relacion Grupos en Conflicto

Figura 2. Puntajes medios de Sinceridad Percibida de las disculpas, Utilidad para comprender el sufrimiento de las víctimas y utilidad para mejorar las relaciones entre grupos.

La tabla 6 muestra los puntajes obtenidos en confianza institucional para cada institución. Se observa que las instituciones gubernamentales tienen sin excepción, puntajes por debajo de la media teórica, mientras que las instituciones no gubernamentales puntajes más altos en todos los casos. Los puntajes de confianza más altos de todas las instituciones son los referentes a las universidades y a los líderes sociales. 


\section{Tabla 6}

Puntajes medios y desviación estándar de confianza en las instituciones

\begin{tabular}{lc}
\hline Instituciones & $M(D E)$ \\
\hline 1. Poder Ejecutivo & $1.53(.69)$ \\
2. Poder Legislativo & $1.58(.70)$ \\
3. Poder Judicial & $1.77(.79)$ \\
4. Gobiernos Departamentales & $1.62(.68)$ \\
5. Gobiernos Locales & $1.66(.71)$ \\
6. Partidos políticos & $1.41(.59)$ \\
\hline Total Gubernamentales & $1.62(.54)$ \\
\hline 7. Sindicatos & $2.17(.91)$ \\
8. ONGs & $2.11(.89)$ \\
9. Líderes sociales & $2.68(.96)$ \\
10. Universidades & $2.73(.89)$ \\
11. JEP & $2.35(.94)$ \\
12. Comisión de la Verdad & $2.38(.91)$ \\
\hline Total No Gubernamentales & $2.40(.69)$ \\
\hline
\end{tabular}

En cuanto a la confianza gubernamental, se encontraron diferencias significativas entre regiones $[F(5.1160)=4.061 ; p=.001 ; \eta 2=$ .017], siendo el Centro Oriente $(M=1.76 ; D E=.60)$, el de mayor puntaje y el Pacífico $(M=1.56 ; D E=.53)$, el de menor. No se encontraron diferencias en género, posición política ni victimización.

\section{Emociones negativas, positivas y de trascendencia vinculadas al trabajo de la Comisión}

Los resultados descriptivos de la muestra total, con relación a las emociones negativas, positivas y de trascendencia pueden observarse en la tabla 3. En las emociones negativas se encontraron diferencias con respecto a la victimización, siendo las víctimas las que más emociones negativas reportan $[F(1,1164)=11.956 ; p=.001 ; \eta 2=.010], y$ 
a la posición política, donde las personas autodenominadas de derecha, tienen mayor puntaje de emociones negativas $[F(2,1163)=7.202$; $p=.001 ; \eta 2=.012]$.

En las emociones de trascendencia, se situaron en la media teórica, siendo la cercanía/amor al prójimo y el estar profundamente conmovido, los ítems con mayor activación; aun así, en general las cuatro emociones estudiadas (Cercanía, Crecimiento, Elevación, Conmovido), tienen valores bajos-de 1 y 2 en un rango de respuesta de 1 a 4) en la escala (Ver figura 3). Se encontraron diferencias estadísticamente significativas, el tamaño del efecto fue pequeño $[F(1,1164)=7.554$; $p=.006 ; \eta 2=.006]$, sin embargo, no se encontraron diferencias en cuanto a género o posición política. En cuanto a las emociones positivas, por el contrario, no se encontraron diferencias en cuanto a la victimización, pero si en relación con la posición política, siendo en este caso los participantes de izquierda $(M=2.29 D E=.96)$, los que más emociones positivas reportan en comparación con las personas de centro $(M=2.06 D T=.89 ; p=.0001)$ y de derecha $(M=2.12 D E=.95$; $p=.046)[F(2,1163)=7.466 ; p=.001 ; \eta 2=.013]$.

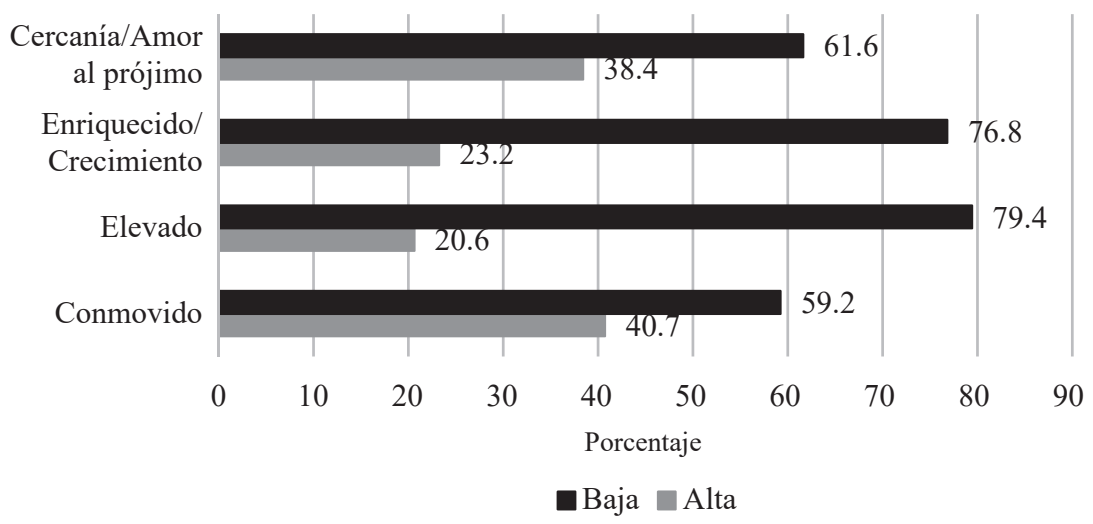

Figura 3. Porcentajes de emociones de trascendencia de la muestra total. Reconciliación social y actitudes hacia el recuerdo. 
La muestra total tiene una puntuación media-alta en la escala de reconciliación social. Los ítems de la escala fueron analizados a partir de los valores altos (puntajes de 3 y 4 ) y bajos (puntajes de 1 y 2). Se encuentra que el ítem con menor acuerdo entre los participantes es "Que las victimas mantengan su indignación por lo ocurrido y lo expresen públicamente"; este resultado es similar en todas las regiones del país. En contraposición, el ítem "Que los victimarios lleven a cabo acciones reales de reparación” fue el de mayor acuerdo en el país y todas las regiones (Ver tabla 7).

\section{Tabla 7}

Porcentaje de acuerdo con los items de la escala de reconciliación social

\begin{tabular}{|c|c|c|c|c|c|c|}
\hline Ítems de reconciliación & Total & Caribe & $\begin{array}{l}\text { Centro } \\
\text { Oriente }\end{array}$ & $\begin{array}{l}\text { Centro } \\
\text { Sur }\end{array}$ & $\begin{array}{c}\text { Llanos } \\
\text { Orientales }\end{array}$ & Pacífico \\
\hline $\begin{array}{l}\text { Que los victimarios pidan perdón } \\
\text { con sinceridad }\end{array}$ & $66 \%$ & $71 \%$ & $64 \%$ & $74 \%$ & $65 \%$ & $59 \%$ \\
\hline Mirar al futuro & $75 \%$ & $86 \%$ & $72 \%$ & $79 \%$ & $69 \%$ & $70 \%$ \\
\hline Recordar el pasado pero sin odio. & $64 \%$ & $73 \%$ & $67 \%$ & $74 \%$ & $59 \%$ & $54 \%$ \\
\hline $\begin{array}{l}\text { Que las victimas mantengan su } \\
\text { indignación por lo ocurrido y lo } \\
\text { expresen públicamente. }\end{array}$ & $33 \%$ & $33 \%$ & $25 \%$ & $35 \%$ & $37 \%$ & $32 \%$ \\
\hline $\begin{array}{l}\text { Que los victimarios asuman } \\
\text { su responsabilidad y culpa } \\
\text { por lo ocurrido expresándolo } \\
\text { públicamente. }\end{array}$ & $70 \%$ & $80 \%$ & $65 \%$ & $77 \%$ & $70 \%$ & $61 \%$ \\
\hline $\begin{array}{l}\text { Que víctimas y victimarios } \\
\text { sientan que pese a todo forman } \\
\text { una comunidad que comparten } \\
\text { intereses y destino. }\end{array}$ & $56 \%$ & $61 \%$ & $55 \%$ & $74 \%$ & $46 \%$ & $48 \%$ \\
\hline $\begin{array}{l}\text { Que víctimas y victimarios } \\
\text { convivan calmadamente, sin } \\
\text { temor a agresiones. }\end{array}$ & $61 \%$ & $70 \%$ & $64 \%$ & $70 \%$ & $52 \%$ & $54 \%$ \\
\hline $\begin{array}{l}\text { Que los victimarios lleven a cabo } \\
\text { acciones reales de reparación. }\end{array}$ & $81 \%$ & $90 \%$ & $80 \%$ & $87 \%$ & $74 \%$ & $74 \%$ \\
\hline
\end{tabular}

Nota: Los porcentajes representan los valores de alto acuerdo (3 y 4) de la escala de reconciliación social. 
Se encontraron diferencias estadísticamente significativas en la reconciliación social en cuanto a la región (ver tabla 8.), pero no en victimización, posición política o género.

\section{Tabla 8}

Diferencias entre regiones en las variables de reconciliación social y actitudes hacia el recuerdo

\begin{tabular}{|c|c|c|c|c|c|c|c|c|c|}
\hline \multirow[b]{2}{*}{ Variables } & \multicolumn{6}{|c|}{ Región } & \multirow[b]{2}{*}{$F$} & \multirow[b]{2}{*}{$p$} & \multirow[b]{2}{*}{$\eta^{2}$} \\
\hline & $\begin{array}{l}\text { Caribe } \\
M(D T)\end{array}$ & $\begin{array}{l}\text { Centro } \\
\text { Oriente } \\
M(D T)\end{array}$ & $\begin{array}{l}\text { Centro } \\
\text { Sur } \\
M(D T)\end{array}$ & $\begin{array}{c}\text { Eje } \\
\text { Cafetero } \\
M(D T)\end{array}$ & $\begin{array}{c}\text { Llanos } \\
\text { Orientales } \\
M(D T)\end{array}$ & $\begin{array}{l}\text { Pacífico } \\
M(D T)\end{array}$ & & & \\
\hline $\begin{array}{l}\text { Reconciliación } \\
\text { Social }\end{array}$ & $\begin{array}{l}3.04^{\mathrm{a}} \\
(.61)\end{array}$ & $\begin{array}{l}2.82^{\mathrm{bd}} \\
(.68)\end{array}$ & $\begin{array}{l}3.04^{c} \\
(.62)\end{array}$ & $\begin{array}{l}3.26 \\
(.39)\end{array}$ & $\begin{array}{l}2.77^{\text {bd }} \\
(.72)\end{array}$ & $\begin{array}{l}2.71^{\text {bd }} \\
(.74)\end{array}$ & 10.454 & .000 & .043 \\
\hline $\begin{array}{l}\text { Aprender de los } \\
\text { errores del pasado }\end{array}$ & $\begin{array}{l}3.59^{\mathrm{a}} \\
(.74)\end{array}$ & $\begin{array}{l}3.32^{\mathrm{bc}} \\
(.85)\end{array}$ & $\begin{array}{l}3.37^{\mathrm{bc}} \\
(.84)\end{array}$ & $\begin{array}{l}3.43 \\
(.53)\end{array}$ & $\begin{array}{l}3.15^{\mathrm{b}} \\
(1.0)\end{array}$ & $\begin{array}{c}3.00^{\text {bd }} \\
(1.0)\end{array}$ & 12.937 & .000 & .053 \\
\hline $\begin{array}{l}\text { Olvidar el pasado } \\
\text { de violencia }\end{array}$ & $\begin{array}{l}2.04^{\mathrm{a}} \\
(1.0)\end{array}$ & $\begin{array}{l}2.09^{\mathrm{a}} \\
(1.0)\end{array}$ & $\begin{array}{l}1.79^{\mathrm{bc}} \\
(.96)\end{array}$ & $\begin{array}{l}2.71 \\
(1.1)\end{array}$ & $\begin{array}{l}2.47^{\mathrm{bd}} \\
(1.15)\end{array}$ & $\begin{array}{l}2.04^{\mathrm{a}} \\
(1.04)\end{array}$ & 9.657 & .000 & .040 \\
\hline
\end{tabular}

Nota: Diferentes letras indican diferencias estadísticamente significativas (post-hoc DMS) $(p<.05)$

En cuanto a las actitudes hacia el recuerdo del pasado, en todas las regiones se observa puntuaciones más altas en el ítem relacionado con el recuerdo (Aprender de los errores del pasado), que con el ítem relacionado con el olvido (Olvidar el pasado de violencia). Los resultados son similares a los encontrados en otros siete países de Sudamérica (ver Tabla 5). Las diferencias entre regiones en cada ítem, pueden observarse en la tabla 8. En general, la región del caribe tuvo la puntuación más alta en el ítem relacionado con el recuerdo, diferenciándose significativamente del Centro Oriente, Centro Sur, Llanos Orientales y Pacífico. En cuanto al olvido, los Llanos Orientales tuvieron la puntuación más alta, diferenciándose significativamente del Caribe, Centro Oriente, Centro Sur y Pacífico. 


\section{Discusión}

Los resultados de este estudio muestran similitudes con lo reportado en otros países de Latinoamérica (Arnoso et al., 2015; Reyes et al., 2015; Mathias et al., 2020). En ese sentido, es importante reconocer que la creación de una instancia estatal para el tratamiento de la violencia colectiva es un paso importante para la reconstrucción de la memoria histórica y sus primeros impactos son, al menos en parte, positivos. Vale la pena destacar, que la realidad sobre la violencia en Colombia, enmarca múltiples realidades históricas, sociales, culturales y económicas, que imposibilitan observar los resultados desde solo un punto de vista general. De esta manera, los resultados destacan las diferencias entre las grandes macrorregiones del país en la mayoría de las variables evaluadas (Conocimiento, aprobación y participación en la Comisión, confianza institucional, reconciliación social, actitudes hacia el recuerdo). Los resultados apuntan a que el conocimiento sobre la comisión es mayoritariamente bajo en todas las regiones, lo cual difiere de lo encontrado en algunos países latinoamericanos y se sitúa por debajo de los países con menor conocimiento (Arnoso et al., 2015). El bajo conocimiento colombiano puede estar relacionado con la baja frecuencia en la que aparecen noticias al respecto de su trabajo y la poca información que reportan ver los participantes en redes sociales, la televisión, la radio y los periódicos.

Un hallazgo interesante, es que tal y como se evidencia en países como Argentina, Chile o Brasil, el conocimiento sobre la comisión está relacionado con la victimización (Reyes et al., 2015), además de con el género, donde los hombres reportan mayor conocimiento. Los resultados, también relacionan la aprobación del trabajo de la comisión con la región del participante, siendo la región del Centro Sur la de mayor aprobación y la de los Llanos Orientales la de menor. La aprobación, tal y como sucede en otros estudios sobre las comisiones (ver Mathias et al., 2020), también se relaciona con la posición política, siendo las personas de izquierda las que más aprueban y las de derecha las que menos; esto, no difiere mucho de lo esperado teniendo en cuenta que 
el acuerdo de paz que conllevó a la creación de la Comisión, fue hecho entre el gobierno y la guerrilla de las FARC-EP, teniendo sus mayores detractores políticos en la derecha y la extrema derecha. Aun así, similar al caso de Perú (Espinosa et al., 2017), la victimización no produjo diferencias en la aprobación, siendo en general, más alta que la media teórica en todo el país. Esto, podría deberse al menos en parte a que, como sucedió en Perú, la victimización no se produjo por medio de un único grupo (e.g. Militares), sino que respondió a una dinámica de violencia colectiva que involucra diversos actores armados con una gran variabilidad de objetivos y corrientes ideológicas.

Es importante mencionar que la disposición a participar en actividades de la comisión fue mayoritariamente alta, y viene acompańada de una alta expectativa en el cumplimiento de los objetivos de la Comisión, más aún cuando se trata de personas víctimas. En ese sentido, los tres objetivos principales de la comisión parecen cumplir con los mínimos necesarios para las necesidades de la población víctima y la población general.

En relación con las disculpas que se han ofrecido en distintos momentos por parte de los grupos en conflicto, Colombia sigue el patrón latinoamericano, es decir, las disculpas se perciben como poco sinceras y eficaces y se cuestiona su utilidad en el contexto de la reparación a las víctimas y la reconciliación con los perpetradores (Arnoso et al., 2015; Reyes et al., 2015, Mathias, 2019). Por otro lado, aun cuando el conocimiento de las disculpas para todos los grupos es generalmente bajo, la cercanía con el proceso de paz y la lejanía con las disculpas del proceso de reinserción paramilitar, podría explicar el mayor conocimiento de disculpas del gobierno Santos y de los líderes de la guerrilla de las FARC.

Otro aspecto a destacar es la baja confianza institucional, mayoritariamente de las instituciones gubernamentales sin discriminación de sus funciones en el país, en contraste con una mayor confianza hacia instituciones o grupos no relacionados con el Estado. Estas situaciones, son esperables en un contexto de violencia colectiva y de conflictos intratables que perduran durante un largo periodo de tiempo, donde 
el tejido social ha sido fracturado y la eficacia institucional, así como la presencia estatal es mínima (Staub, 2012).

Transversal a todo lo anterior, las emociones negativas están más presentes en las víctimas. Estudios anteriores, han constatado el coste emocional que deriva de revivir las historias traumáticas, aumentando las emociones negativas de los implicados (Arnoso et al., 2015). Por otro lado, la posición política está relacionada tanto con las emociones positivas, como con las negativas de manera opuesta. Por un lado, las personas de izquierda, reportan más emociones positivas, mientras que las personas de derecha, más emociones negativas. En cuanto a las emociones de trascendencia, la cercanía con el prójimo y el estar profundamente conmovido son las de mayor activación, reportando sentirlas 4 de cada 10 personas, lo cual resulta natural debido a la naturaleza de las tareas de la comisión, en las cuales las víctimas y sus historias de victimización son el eje central. Con todo, los resultados reafirman que las actividades de justicia transicional como rituales colectivos movilizan emociones positivas y de trascendencia en un grupo importante de personas (Paez, 2018). Por el contrario, sentirse moralmente elevado o en una experiencia enriquecedora que refieren a un proceso de crecimiento postraumático son las de más baja activación, solo informan sentirlas 2 de cada 10 personas. En estudios con víctimas directas, la mayoría de las personas que participaron en la Comisión de Verdad de Ecuador informaron de niveles de crecimiento postraumático (Reyes et al, 2018). El estudio de Cárdenas et al (2017), con una amplia muestra de víctimas de la dictadura de Pinochet en Chile, encontró que una gran proporción de las víctimas del terrorismo de Estado lograron crecer después de estas experiencias, y la redefinición del sentido de la vida, la revalorización positiva de las experiencias traumáticas y el acuerdo con la reconciliación fueron los elementos que permitieron crear una nueva narrativa sobre el pasado enfatizando los cambios positivos personales y sociales.

Por último, vale la pena mencionar que los índices de reconciliación social, totales y regionales, son en general altos. Aun cuando hay diferencias entre las regiones, el hecho de no haber encontrado 
diferencias significativas en la posición política o la victimización, sugiere un cambio en las concepciones de convivencia pacífica en el país durante los últimos años, ya que, múltiples investigaciones desarrolladas en Colombia durante la segunda década de los 2000, señala una baja disposición hacia la reconciliación y el perdón en la población general (López-López et al., 2012; López- López et al., 2013; López-López et al., 2016). Por otro lado, es interesante que en todas las regiones haya un consenso con respecto a que la indignación de las víctimas expresada públicamente no es necesariamente positiva para la reconciliación social, mientras que la reparación por parte de los victimarios, surge como el eje central de la reconciliación.

En futuros estudios, será importante explorar con mayor profundidad las implicaciones de las diferencias entre las variables en función de la región, la posición política y el género, ya que como se ha visto, parecen ser aspectos transversales a la percepción de la comisión y la construcción de paz desde la reconciliación social y la memoria colectiva. También reconocemos las limitaciones de este estudio. El carácter transversal de la muestra no permite hacer generalizaciones, y algunas regiones del país, específicamente el Eje Cafetero, tiene un tamańo muestral extremadamente pequeño, lo que imposibilita la comparación con otras regiones. La muestra tiene una sobrerrepresentación de victimas (en ese sentido es similar a la muestra ecuatoriana) y por la masividad de la violencia rural se asemeja a la muestra Peruana.

En suma, este estudio explora los primeros impactos del trabajo de la Comisión de la Verdad y encuentra similitudes importantes con otros estudios relacionados a comisiones de la verdad de Latinoamérica. Aun cuando el caso colombiano tiene particularidades que lo hacen un caso especial — debido a la longitud del conflicto, los grupos implicados y el número de víctimas - los aspectos ya mencionados sobre el conocimiento de la comisión, las expectativas sobre sus objetivos, las emociones vinculadas a su desempeño y el rechazo a las disculpas oficiales, son consistentes con otros países. Cabe resaltar que tal y como se esperaba, los resultados se acercan al caso peruano, debido, al menos en parte, a que la historia de violencia en Perú, guarda más similitudes 
con Colombia en relaciones a otros países con historia de violencia política dictatorial. Globalmente, pese a las limitaciones de la actividad de la Comisión en el contexto de post violencia "irreal", por la continuidad de las muertes de líderes sociales, ex guerrilleros, así como de la presencia de grupos armados y con un Gobierno contrario a los acuerdos de paz, la encuesta muestra un perfil positivo de la actitud y disposición de los colombianos hacia los objetivos de esta instancia de justicia transicional.

\section{Referencias}

Arnoso, M., Cárdenas, M., Páez, D. y Martín-Beristain, C. (2014). Paraguay: De las violaciones a los derechos humanos a la justicia transicional. Salud y Sociedad, 5(1), 098-114. https://doi.org/ ISSN 0718-7475

Arnoso-Martínez, M., Páez, D., Cárdenas, M., Zubieta, E., Espinosa, A. y Bilbao, M. (2015). Representaciones sociales del pasado y rituales de justicia transicional en América Latina. Cuadernos de Pesquisa, 45(156), 276-298. https://doi. org/10.1590/198053143134

Blanca, M. J., Alarcón, R., Arnau, J., Bono, R. y Bendayan, R. (2017). Non-normal data: Is ANOVA still a valid option? Psicothema, 29(4), 552-557. https://doi.org/10.7334/psicothema2016.383

Beristain, C. M. (2016). Una comisión de la verdad para Colombia. El derecho a la verdad como fundamento de la construcción de paz reflexiones sobre una comisión de la verdad para Colombia (2) 83-107.

Cárdenas, M., Páez, D. y Rimé, B. (2013). El impacto psicosocial de los procesos transicionales en Chile: Evaluación de los efectos de las comisiones nacional de "verdad y reconciliación" y "prisión política y tortura”. Revista de Psicología Social, 28(2), 145. https://doi.org/10.1174/021347413806196717 
Cárdenas-Castro M., Faúndez-Abarca X., Arancibia-Martini H., Y Ceruti-Mahn C. (2021). The Relationship Between Posttraumatic Growth and Psychosocial Variables in Survivors of State Terrorism and Their Relatives. Journal of Interpersonal Violence. 36(1-2), 428-447. https://doi.org/10.1177/0886260517727494 Cusi, O., Pizarro, J. J., Alfaro-Beracoechea, L., Paéz, D. y Carrera, P. (2018). Elevación o inspiración moral: creación y validación de una escala de elevación en castellano. Artículo en preparación. Revista Latinoamericana de Psicología Positiva, 4, Special Issue.

Espinosa, A., Páez, D., Velázquez, T., Cueto, R. M., Seminario, E., Sandoval, S., Reátegui, F. y Jave, I. (2017). Between remembering and forgetting the years of political violence: Psychosocial impact of the Truth and Reconciliation Commission in Peru. Political Psychology, 38(5), 849-866. https://doi.org/10.1111/ pops. 12364

Hamber, B. (2007). Forgiveness and reconciliation: Paradise lost or pragmatism? Peace and Conflict, 13(1), 115-125. https://doi. org/10.1037/h0094027

Hervás, G. y Vázquez, C. (2013). Construction and validation of a measure of integrative well-being in seven languages: the Pemberton Happiness Index. Health and quality of life outcomes, 11, 66. https://doi.org/10.1186/1477-7525-11-66

Jurisdicción Especial para la Paz. (2019). Sistema Integral de Verdad, Justicia, Reparación y No Repetición SIVJRNR (pp. 2-6). Bogotá. Recuperado de https://www.jep.gov.co/Infografas/ SIVJRNR_ES.pdf

López-López, W. (2020). A multidimensional and dynamic perspective of research and intervention in peace psychology. Peace Psychologist, 16-41.

López-López, W., Pineda-Marín, C., Correa-Chica, A., Rincón-Unigarro, C. y Silva, L. M. (2021). Psychology of Peace: Findings and Challenges for the Multidimensional Transformation of Violent Social Practices. En C. Zúñiga y W. López-López (Eds.), 
Political psychology in Latin America (pp. 131-150). https://doi. org/10.1037/0000230-000

López-López, W., Marín, C. P., León, M. C. M., Garzón, D. C. P. y Mullet, E. (2012). Colombian lay people's willingness to forgive different actors of the armed conflict: Results from a pilot study. Psicologica. 33(3), 655-663.

López- López, W., Pineda, C., Murcia, C., Perilla, C. y Mullet, E. (2013). Colombian lay people's willingness to forgive different actors of the armed conflict: results from a pilot study. Psicologica: International Journal of Methodology and Experimental Psychology, 33(3), 655-663.

López-López, W., Silva, L. M., Castro Abril, P. y Caicedo, A. (2016). Actitudes implícitas de estudiantes universitarios frente al perdón en el marco del conflicto armado colombiano. Pensamiento Psicológico, 14(2), 49-62. https://doi.org/10.11144/Javerianacali. PPSI14-2.aieu

Martín-Beristain, C., Páez, D., Rimé, B. y Kanyangara, P. (2011) La superación de la violencia colectiva: impactos y problemas de los rituales de la justicia transicional. En D. Páez, C. M. Beristain, J. L. González-Castro, N. Basabe, J. de Rivera (Eds.), Superando la violencia colectiva y construyendo cultura de paz (pp. 475-492). Fundamentos.

Mathias, A. (2019). Who controls the present controls the past? Psychosocial effects of the Truth Commission's evaluation and the social representations of history in Brazil (Doctoral dissertation). University of the Basque Country, Donostia-San Sebastián, Spain.

Mathias, A., Páez, D., Espinosa, A., Sandoval, S., Alzugaray, C., Arnoso, M., Cárdenas, M., da Costa, S., Reyes, C., Rimé, B. y Zubieta, E. (2020). The association between Truth Commissions evaluation, emotional climate and institutional trust: comparison and meta-analysis of surveys in six South American countries (La relación entre la evaluación de las Comisiones de la Verdad, el clima emocional y la confianza institucional: comparación y metaanálisis de encuestas en seis países de América del Sur). 
Revista de Psicologia Social, 35(2), 203-245. https://doi.org/10.1 080/02134748.2020.1721053

Mullet, E., Pinto, M-C., Nann, S., Kadiangandu, J. y Neto, F. (2011) Hacia una política positiva: el caso del perdón en el contexto intergrupal en Asia y Africa. En D. Páez, C.M. Beristain, J.L. González-Castro, N. Basabe, J. de Rivera (Eds.), Superando la violencia colectiva y construyendo cultura de paz (pp. 377-398). Fundamentos.

Noor, M., Shnabel, N., Halabi, S. y Doosje, B. (2015). Peace vision and its socio-emotional antecedents: The role of forgiveness, trust, and inclusive victim perceptions. Group Processes \& Intergroup Relations, 18(5), 644-654. https://doi. org/10.1177/1368430215586604

Páez, D., Ruiz, J. I., Gally, O., Kornblit, A. L., Wiesenfeld, E. y Vidal, C. M. (1997). Clima emocional: su concepto y medición mediante una investigación transcultural. Revista de Psicología Social, 12(1), 79-98. https://doi.org/10.1174/02347497320892045

Paez, D. R. y Liu, J. H.-F. (2011). Collective memory of conflicts. En D. Bar-Tal (Ed.), Frontiers of social psychology. Intergroup conflicts and their resolution: A social psychological perspective (pp. 105-124). Psychology Press.

Paez, D. (2018). Bienestar, emociones positivas grupales, de trascendencia, espiritualidad y conductas sociales: correlatos y efectos. Revista Latinoamericana de Psicología Politica, 4, 1-10.

Registro Único de Víctimas. (2020). Unidad de Víctimas Gobierno Nacional.

Reyes, C., Grondona, G. y Rodriguez, M. (2015). Evaluación del impacto de la Comisión de la Verdad en Ecuador: aportes psicosociales en la actual discusión sobre la reparación a las víctimas. Psicología Politica, 15(32), 119-136.

Reyes, C., Grondona, G., Rodriguez, M. y Páez, D. (2018) Post traumatic Growth of Victims informed by the Truth Commission of Ecuador. Revista Interamericana de PsicologialInteramerican Journal of Psychology, 52(3), 379-388. 
Rimé, Bernard. (2012). La compartición social de las emociones. Bilbao: Desclée de Brouwer, S.A.

Ruiz, J. I. (2010). Actitudes sociales hacia ex reclusos: Un estudio exploratorio. Suma Psicologica, 17(2), 169-177.

Ruiz Pérez, J. I. (2015). Resiliencia comunitaria: propuesta de una escala y su relación con indicadores de violencia criminal. Pensamiento Psicológico, 13(1). https://doi.org/10.11144/javerianacali.ppsi13-1.rcpe

Staub, E. (2012) Genocide, Mass Killing, and Violent Conflict: Prevention and Reconciliation. En L.R. Tropp (Ed.), The Oxford Handbook of Intergroup Conflict (pp. 309-327). University Press.

Trejos, L. F. (2013). Colombia: Una revisión teórica de su conflicto armado. Revista Enfoques: Ciencia Politica y Administración Pública, XI(18), 55-75.

Wohl. M. J. A., Y Branscombe, N. R. (2005). Forgiveness and collective guilt assignment to historical perpetrator groups depend on level of social category inclusiveness. Journal of Personality and Social Psychology, 88, 288-303. https://doi. org/10.1037/0022-3514.88.2.288

Recibido : 2020-02-10

Revisado : 2021-05-14

Aceptado 2021-10-22 